\title{
PENGEMBANGAN SEKOLAH ADAT UNTUK MENUNJANG DESA WISATA DI DESA MAS KECAMATAN UBUD KABUPATEN GIANYAR
}

\author{
W. Windia ${ }^{1}$, I.G.L.O. Cakra ${ }^{2}$, N.G.K. Roni ${ }^{3}$ dan I.N. Sujana ${ }^{4}$
}

\begin{abstract}
ABSTRAK
Pengembangan desa Mas sebagai desa wisata budaya perlu didukung oleh atraksi wisata yang unik berbasis potensi lokal. Pengabdian Masyarakat ini bertujuan untuk pengembangan sekolah adat budaya Bali sebagai atraksi wisata untuk mendukung desa wisata Mas. Metode pelaksanaan meliputi sosialisasi dan berdiskusi dengan kepala desa, pimpinan desa adat, dan tokoh-tokoh masyarakat mengenai pengembangan sekolah adat budaya Bali, menjalin kerjasama dengan musium Mangku Pendet tentang pemakaian areal dan fasilitas musium untuk penyelenggaraan sekolah adat budaya Bali, bimbingan teknis kepada pengelola dan evaluasi. Hasil pengabdian menunjukkan bahwa program pengembangan sekolah desa adat mendapat dukungan positif dari pimpinan desa dan para pemangku kepentingan, sebanyak 10 orang pengelola dan 2 orang narasumber telah siap mendukung operasional sekolah, serta sekolah adat telah mampu menjadi atraksi wisata dicirikan oleh berjalannya paket belajar adat budaya Bali secara kontinyau.
\end{abstract}

Kata kunci : sekolah, adat budaya Bali, atraksi wisata, desa, wisata.

\begin{abstract}
The development of Mas village as a cultural tourism village needs to be supported by unique tourism attractions based on local potential. This Community Service aims to develop Balinese cultural schools as a tourist attraction to support the Mas tourism village. Implementation methods include socializing and discussing with village heads, customary village leaders, and community leaders regarding the development of a Balinese traditional culture school, establishing cooperation with the Mangku Pendet museum on the use of area and museum facilities for organizing a Balinese traditional culture school, technical guidance to the manager and evaluation. The results of the dedication show that the customary village school development program received positive support from the village leadership and stakeholders, as many as 10 managers and 2 resource persons were ready to support the school's operations, and the traditional school has been able to become a tourist attraction characterized by the running of a traditional Balinese culture learning package continuously..
\end{abstract}

Keywords: schools, Balinese culture, tourist attractions, tourist villages.

\section{PENDAHULUAN}

Desa Mas termasuk ke dalam wilayah administratif Kecamatan Ubud Kabupaten Gianyar, berada pada ketinggian antara 450 - $700 \mathrm{~m}$ dpl dengan luas wilayah 4,65 km². Jumlah penduduk Desa Mas 11.934 jiwa

\footnotetext{
${ }^{1}$ Program Studi Ilmu Hukum Fakultas Hukum Universitas Udayana, wayan_windia@unud.ac.id

${ }^{2}$ Program Studi Ilmu Peternakan Fakultas Peternakan Universitas Udayana, oka_cakra@unud.ac.id

${ }^{3}$ Program Studi Ilmu Peternakan Fakultas Peternakan Universitas Udayana

${ }^{4}$ Program Studi Bahasa Indonesia Fakultas Sastra Universitas Dwijendra
} 
Untuk menuju Desa Mas ini berjarak sekitar $20 \mathrm{~km}$ dari Ibu kota Denpasar, dari Gianyar berjarak kurang lebih $10 \mathrm{~km}$ sementara dari kota kecamatan Ubud berjarak $6 \mathrm{~km}$. Karena letaknya yang strategis berada di jalur wisata Denpasar, Ubud, Tampaksiring dan Kintamani membuat desa ini mudah di kunjungi dan jarang di lewatkan oleh para wisatawan yang ingin melihat pembuatan karya seni maupun membeli karya seni untuk cinderamata ke tempat asal.

Pemuka adat dan komponen pariwisata Desa Mas, Kecamatan Ubud, Kabupaten Gianyar, Bali berencana mengembangkan desa tersebut menjadi desa wisata yang berbasis adat dan budaya. Dalam mengembangkan desa wisata, desa bersangkutan harus memiliki atraksi yang unik dan khas yang berbeda dengan desa lainnya (Sardiana dan Ramaswati, 2015; Sardiana, 2018). Strategi yang dilakukan adalah dengan mengundang wisatawan untuk mengenal lebih dekat seni budaya masyarakat di desa itu. Wisatawan mancanegara yang akan diundang itu nantinya akan tinggal di rumah-rumah penduduk dalam kurun waktu sepekan hingga tiga pekan atau sesuai dengan permintaan dari wisatawan tersebut. Selama tinggal, mereka akan diperlakukan seperti bagian dari keluarga sendiri dalam melakukan aktivitas sehari-hari Misalnya kalau tamu itu senang seni mematung, mereka akan diajarkan memahat patung, kalau tertarik mengikuti aktivitas adat wisatawan dapat membaur melaksanakan aktivitas adat dengan masyarakat lokal, dan sebagainya . Penduduk desa menjadi pelaku utama dalam pengembangan desa wisata ini (Sardiana dan Ramaswati, 2016; Ramaswati and Sardiana, 2017).

Untuk itu perlu penyediaan sarana prasarana yang memadai, misalnya sudah tersedia rumah-rumah penduduk yang siap dihuni oleh wisatawan. Artinya masing-masing rumah tangga yang siap dihuni turis itu harus memenuhi standar, dan yang lebih penting adalah sikap warga agar memiliki hospitality dan sadar sapta pesona sehingga wisatawan merasa nyaman. Sapta Pesona merupakan kondisi yang harus diwujudkan dalam rangka menarik minat wisatawan berkunjung ke suatu daerah atau wilayah. Sapta Pesona terdiri dari tujuh unsur yaitu aman, tertib, bersih, sejuk, indah, ramah tamah dan kenangan. Selain itu perlu juga disediakan atraksi atau aktivitas wisata yang menarik sehingga wisatawan betah berlama-lama tinggal di desa tersebut (Sardiana, 2018). Ataraksi atau aktivitas wisata tersebut harus unik berbeda dengan atraksi wisata yang sudah ada ditempat lainnya. Daya tarik dan aktivitas wisata yang potensial dikembangkan adalah arboretum tanaman etnobotani bali yang mengoleksi berbagai jenis tanaman yang terkait dengan budaya Bali seperti untuk kegiatan ritual dan pengobatan/usada yang disebut taru premana, yang terintegrasi dengan daya tarik populasi monyet yang telah dijinakkan. Untuk memberikan kekhasan desa wisata dibandingkan dengan desa wisata lainnya di Bali, Desa Mas bekerjasama dengan museum Pendet berencana membangun sekolah adat budaya Bali sebagai daya tarik wisata.

\section{METODE PELAKSANAAN}

Dalam implementasi pendekatan tersebut pembinaan sumberdaya manusia (SDM) menjadi sangat penting. Beberapa pendekatan pembinaan yang dilakukan adalah melalui penyuluhan, pelatihan, dan pendampingan. Penyuluhan adalah upaya transfer inovasi kepada masyarakat sasaran melalui kegiatan ceramah dan simulasi aplikasi Iptek. Pelatihan adalah proses penyelenggaraan belajar mengajar dalam rangka meningkatkan kapasitas, kemampuan dan ketrampilan peserta. Sebagai tindak lanjut kegiatan pelatihan, maka untuk meningkatkan keterampilan SDM dalam aplikasi teknologi, pengelolaan/pengembangan usaha maka dilakukan program pendampingan. Tenaga pendamping ini berasal dari dosen yang berkompeten di bidangnya dan mahasiswa yang menetap di desa sasaran.

Pelaksanaan kegiatan di lapangan dilakukan melalui beberapa tahapan yaitu :

(1) Sosialisasi dan kordinasi pelaksanaan program kepada stakeholder, seperti SKPD terkait, camat, kepala desa, kelompok sasaran. 
(2) Pelaksanaan kegiatan penyuluhan, bimbingan teknis, dan pendampingan kepada masyarakat sasaran sesuai dengan rencana kegiatan yang telah disusun.

a. Pengembangan sekolah adat sebagai wahana edukasi adat Bali dan paket desa wisata budaya

b. Penguatan kelembagaan pengelola sekolah adat budaya Bali

c. Peningkatan fasilitas wisata berbasis masyarakat (home stay dari rumah penduduk)

d. Peningkatan kompetensi SDM desa sebagai pelaku pariwisata (Pendampingan pengolahan kuliner yang sesuai standar sanitasi higenies; Pelatihan bahasa asing bagi pengelola home stay)

e. Temu usaha dan penentuan strategi kemitraan pemasaran

f. Membuat media promosi dan pemasaran berbasis IT

(3) Monitoring dan evaluasi pelaksanaan kegiatan

Dalam rangka mengawal agar kegiatan berjalan sesuai dengan rencana dan target luaran maka pelaksanaannya dipantau secara berkala. Evaluasi dilakukan untuk menilai keberhasilan program, evaluasi dilakukan menyangkut tiga aspek yaitu aspek kognitif yaitu perubahan pemahaman kelompok sasaran/mitra, aspek afektif atau perubahan sikap mitra, serta aspek psikomotorik atau perubahan keterampilan yang terjadi pada mitra dampak dari Ipteks yang ditransfer/dialihkan kepada masyarakat.

\section{HASIL DAN PEMBAHASAN}

Pelaksanaan kegiatan Pengabdian kepada Masyarakat di kedua mitra dapat berjalan dengan baik dan dengan peran serta mitra yang cukup tinggi (Tabel 3.1), dimana kegiatan penyuluhan dan pelatihan singkat yang diikuti oleh $100 \%$ anggota mitra dan pada kegiatan tersebut 53,3\% anggota mitra telah memahami pentingnya usaha penangkaran benih sebagai usaha potensial untuk meningkatkan pendapatan petani, serta sebanyak $40 \%$ peserta talah memahami tahapan proses penangkaran benih.

Tabel 3.1. Partisipasi Mitra dalam Kegiatan

\begin{tabular}{|r|l|c|c|}
\hline \multirow{2}{*}{ No } & \multicolumn{1}{|c|}{ Kegiatan } & \multicolumn{2}{|c|}{ Mitra I } \\
\cline { 3 - 4 } & & Jumlah & $\%$ \\
\hline A & Kegiatan Penyuluhan - Pelatihan Singkat & & \\
\hline 1 & Absensi/Kehadiran & 20 & 100 \\
\hline 2 & Arti penting sekolah adat & 10 & 53,3 \\
\hline 3 & Pengenalan sapta pesona & 8 & 40 \\
\hline 4 & Terampil dalam mengelola sekolah adat & 5 & 100 \\
\hline 5 & Mampu mengembangkan modul sekolah adat & 4 & 25 \\
\hline
\end{tabular}

Begitu juga dengan kegiatan pembuatan Demoplot mendapatkan partisipasi yang tinggi dari peserta $(100 \%)$, dan yang aktif mengunjungi demplot sebanyak $73,3 \%$. Sementara peserta yang dapat menentukan waktu panen dan teknik panen dengan baik sebanyak 55\%, penanganan pascapanen sebanyak $40 \%$, serta mampu melakukan analisis usaha sebanyak $20 \%$. 


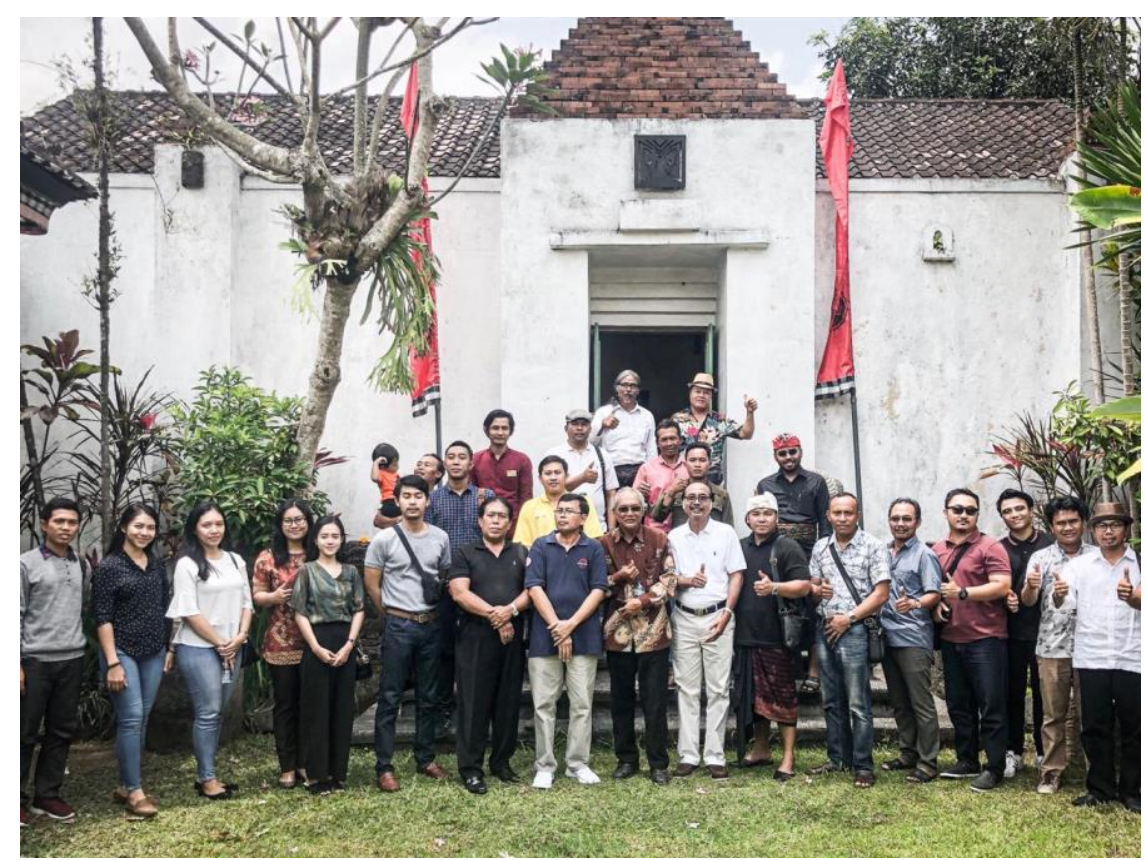

Gambar 3.1. Peserta Sekolah Adat Budaya Bali (Sumber : koleksi pribadi)

Dari kegiatan Bimbingan teknis pengembangan desa wisata diperoleh pemahaman bahwa paket wisata adalah wisata paket disusun dengan harga tertentu. Harga paket wisata pada umumnya sudah termasuk semua komponen yang termasuk kedalam wisata, seperti transportasi, makan, akomodasi, guide, dan lain-lain. Program wisata paket disusun secara lengkap, sehingga wisatawan jika tidak dapat mengikuti program secara keseluruhan, ia dapat menuntut kompensasi atas program yang tidak diikuti, kecuali atas perjanjian tertentu.

Core produk wisata yang ditawarkan berbasis wisata perdesaan yaitu menikmati keindahan alam pedesaan dan aktivitas sehari-hari masyarakat berbasis adat dan budaya Bali. Paket wisata desa adat dan budaya menawarkan kepada wisatawan untuk menetap tinggal menginap di rumah-rumah penduduk yang telah sesuai standar dan mengikuti kehidupan sehari-hari masyarakat yang penuh dengan kegiatan adat dan budaya. Warga desa dapat bertindak sebagai pengelola paket wisata, sementara ibu-ibu bertindak sebagai pengelola rumah tinggalnya masing-masing sebagai penginapan termasuk menyediakan makanan bagi wisatawan. Wisatawan dapat menetap lebih lama untuk mempelajari adat dan budaya Bali secara lebih mendalam di sekolah adat dan budaya Bali yang dikelola oleh pihak desa. Sementara daya tarik wisata alam yang ditawarkan yaitu hutan alami dengan populasi monyet yang sudah dijinakkan, dan arboretum etnobotani Bali. Etnobotani Bali adalah beragam jenis tanaman yang sangat erat kaitannya dengan kehidupan masyarakat Bali seperti tanaman untuk ritual dan pengobatan/usada. Paket wisata tersebut perlu didukung fasilitas penunjang seperti tempat menjual souvernir, tempat minum (kelapa muda) dan kuliner. Penataan rumah penduduk untuk difungsikan sebagai tempat bermalam sesuai standar juga diperlukan bagi wisatawan yang menginap.

Produk wisata atau paket wisata disusun dengan mendeskripsikan ragam objek atau atraksi yang ditawarkan, lama paket, dan harga paket. Produk tersebut disusun dalam bentuk brosur yang menarik. Brosur tersebut, selain berfungsi sebagai sumber informasi yang memberi kepastian kepada wisatawan yang dating, juga sebagai sarana promosi bagi calon wisatawan.

Rekayasa social pengembagan kompetensi dalam mengemas daya tarik wisata menjadi paket wisata agar menarik dan harganya wajar/standar sehingga wisatawan tertarik untuk membeli paket wisata tersebut perlu dilakukan terhadap pengelola wisata. 


\section{KESIMPULAN}

Berdasarkan pembahasan di atas, maka dapat disimpulkan sebagai berikut:

(1) Peserta pengabdian masyarakat memberikan partisipasi yang cukup tinggi yaitu tingkat kehadiran mencapai $100 \%$ anggota mitra, $53,3 \%$ peserta memahami pentingnya usaha pengembangan sekolah adat untuk menunjang desa wisata, sebanyak $40 \%$ faham tentang sapta pesona, serta .sebanyak $25 \%$ telah terampil mengoperasionalkan sekolah adat

(2) Program pengembangan sekolah desa adat mendapat dukungan positif dari pimpinan desa dan para pemangku kepentingan, sebanyak 10 orang pengelola dan 2 orang narasumber telah siap mendukung operasional sekolah, serta sekolah adat telah mampu menjadi atraksi wisata dicirikan oleh berjalannya paket belajar adat budaya Bali secara kontinyau.

\section{UCAPAN TERIMA KASIH}

Tulisan ini merupakan hasil kegiatan Prgram Pengembangan Kemitraan Wilayah (PKW). Penulis menyampaikan terima kasih sebesar-besarnya kepada Direktorat Riset dan Pengabdian kepada Masyarakat Kemenristekdikti yang telah memberikan pembiayan pelaksanaan kegiatan PKW di Desa Mas, Kecamatan Ubud, Gianyar.

\section{DAFTAR PUSTAKA}

Purnawan, NLR., I.K Sardiana. 2017. Paket Wisata Edukasi Subak Upaya Menjaga Keberlanjutan Potensi Pertanian dan Pariwisata Berbasis Budaya di Bali. Jurnal Kawistara 7 (3), 275-284

Sardiana, IK., IWP Windia. 2018. Pemetaan Partisipatif melalui Aplikasi GPS untuk Mitigasi Kon ik Batas Wilayah: Studi Kasus di Desa Adat Nyuh Kuning, Ubud, Bali. Jurnal Kajian Bali (Journal of Bali Studies) 8 (1), 145-158

Sardiana, IK. 2018. The Study of Development of Urban Farming Agrotourism Subak-Irrigation-Based in Sanur Tourism Area, Denpasar City, Bali. Journal of Indonesian Tourism and Development Studies 6 (1), 33-40

Sardiana, IK., NLR Purnawan., 2016. Indigenous community, ecotourism and sustainability: Experience from Tenganan Dauh Tukad traditional. Heritage, Culture and Society: Research agenda and best practices in the hospitality and tourism ind | vol: | issue : |2016-01-01| Conference Proceedin

Sardiana, IK., NLR Purnawan. 2015. Community-based Ecotourism in Tenganan Dauh Tukad: An Indigenous Conservation Perspective. Jurnal Kajian Bali (Journal of Bali Studies) 5 (2), 347-368 